\title{
$\widehat{A}$ Madridge
}

madridge Journal of Internal and Emergency Medicine

\author{
Interconnecting Scientific World
}

Research Article

Open Access

\section{Bivalirudin Efficiency to improve the Coronary flow of Obstructive Coronary Artery Patients}

\begin{abstract}
Maddury Jyotsna ${ }^{1 \star}$, Garre Indrani $^{2}$, K. Sridhar Babu ${ }^{3}$ and RNV Narendra Kumar ${ }^{4}$
${ }^{\prime}$ Professor and HOU-IV, Department of Cardiology, Specialty Block Second Floor, Nizam's Institute of Medical Sciences (NIMS), Hyderabad, India ${ }^{2} P h D$ student, Department of Cardiology, Specialty Block Second Floor, Nizam's Institute of Medical Sciences (NIMS), Pujagutta, Hyderabad, India ${ }^{3}$ Consultant Cardiologist, Department of Cardiology, KIMS hospital, Door No 4-12o/A, North, Bypass Road, Mukthinuthalapadu, Ongole AP, India ${ }^{4}$ Lab technician (Cardiovascular Technology), Department of Cardiology, Specialty Block Second Floor, Nizam's Institute of Medical Sciences (NIMS), Pujagutta, Hyderabad, India
\end{abstract}

\section{Article Info}

*Corresponding author:
Maddury Jyotsna
Professor and HOU-IV
Department of Cardiology
Specialty Block Second Floor
Nizam's Institute of Medical Sciences (NIMS)
Hyderabad, India
Tel: +91-9491073627
E-mail: mail2jyotsna@rediffmail.com

Received: January 21, 2019

Accepted: January 23, 2019

Published: January 29, 2019

Citation: Jyotsna M, Indrani G, Babu KS, Kumar RNVN. Bivalirudin Efficiency to improve the Coronary flow of Obstructive Coronary Artery Patients. Madridge J Intern Emerg Med. 2019; 3(1): 110-113.

doi: 10.18689/mjiem-1000125

Copyright: ( 2019 The Author(s). This work is licensed under a Creative Commons Attribution 4.0 International License, which permits unrestricted use, distribution, and reproduction in any medium, provided the original work is properly cited.

Published by Madridge Publishers

\begin{abstract}
Background: Bivalirudin is a direct reversible inhibitor of thrombin. The synthetic 20 amino acid peptide is an active substance. As it facilitates to improve the coronary flow after $\mathrm{PCl}$, we want to observe whether the Bivalirudin can improve the coronary flow before $\mathrm{PCl}$.
\end{abstract}

Methodology: We prospectively recruited patients of the acute coronary syndrome (ACS) excluding ST elevation MI with single significant coronary stenosis undergoing percutaneous coronary intervention $(\mathrm{PCl})$. Immediately after basal culprit vessel angiogram in an appropriate view, $0.75 \mathrm{mg} / \mathrm{kg}$ of Bivalirudin intravenous bolus was started followed by a $1.75 \mathrm{~kg} / \mathrm{mg} /$ hour infusion. Before doing any balloon dilatation or any other treatment to culprit lesion, the angiogram was repeated for the same previous view of the culprit's vessel. TIMI frame count (TFC) was taken as an indicator of coronary flow. TFC of culprit vessel was noted from basal and after Bivalirudin angiogram. Bivalirudin infusion was continued throughout the $\mathrm{PCI}$ procedure.

Results: In 50 eligible Acute Coronary Syndrome patients with the mean age of $54.4 \pm$ 14.72 yrs were recruited in this study. The culprit lesion was in LAD $23(46 \%)$, in LCX in $15(30 \%)$ and RCA lesion in $12(24 \%)$ of patients. $40 \%$ of patients had diabetes. The Mean TFC before Bivalirudin was $16.92 \pm 6.2$ vs. $11.4 \pm 3.8$ after Bivalirudin which was statistically significant $(p=<0.0001)$.

Conclusion: Bivalirudin decrease the TIMI frame count (TFC) in acute coronary syndrome patients, before treating the culprit vessel angioplasty. As TFC depends on the coronary flow, we conclude that Bivalirudin improves coronary flow.

Keywords: Bivalirudin; TIMI (Thrombolysis in Myocardial Infarction) frame count (TFC); Percutaneous Coronary Intervention (PCI); Acute coronary syndrome (ACS); Cardiology.

\section{Introduction}

Bivalirudin is a direct thrombin inhibitor (DTI) polypeptide that reversibly inhibits thrombin by specifically binding both to the catalytic site and to the anion-binding exosite of circulating and clot-bound thrombin. The action of bivalirudin is reversible because thrombin will slowly cleave the thrombin-bivalirudin bond which recovers the active site of thrombin. This transient binding and self-reversing property of bivalirudin result in a biologic half-life of approximately 25 minutes. Bivalirudin offers more benefits compared to heparin, it is less dependent on renal function and has a lower anaphylaxis 
incidence. Bivalirudin does not activate circulating platelets, in contrast to heparin. It also has a platelet inhibitory effect via inhibition of thrombin-mediated platelet aggregation. It is also not inactivated by platelet release reaction components (e.g., Platelet factor 4). As a result, bivalirudin shows anticoagulation levels that are less variable than heparin [1].

Bivalirudin is indicated as an anticoagulant in percutaneous coronary intervention $(\mathrm{PCl})$ patients with acute coronary syndrome (ACS). It is also indicated for use for those at risk of having heparin-induced thrombocytopenia and as an adjuvant along with IIb/IIla (GPI) inhibitor [1].

Heparin has been the main source of anticoagulation during $\mathrm{PCl}$ for decades in patients with angina and ACS [2]. However, the HEAT PPCI trial [3] and the BRIGHT trial [4] both are favoring the use of bivalirudin instead of heparin. Most of the studies seen to immediate and long term outcomes after bivalirudin usage in these ACS patients, but none of the studies, as far as our knowledge, seen the improvement of coronary blood flow without treating the culprit lesion mechanically.

\section{Material and Methods}

Acute coronary syndrome (ACS) excluding ST elevation $\mathrm{MI}$, with single significant coronary stenosis that was undergoing percutaneous coronary intervention ( $\mathrm{PCl}$ ) patients, was recruited prospectively in the study.

The first angiogram of the culprit vessel was taken in different views. One appropriate view which is showing culprit lesion was selected, and again that view was repeated with prolonged cine angiogram, including the whole length of the coronary artery with the myocardial blush. Then, Bivalirudin $0.75 \mathrm{mg} / \mathrm{kg}$ as intravenous bolus was started immediately, followed by an infusion of $1.75 \mathrm{~kg} / \mathrm{mg} / \mathrm{hour}$. Then the angiogram of the culprit vessel was repeated in the same previous view, 3 minutes after starting the infusion. The TFC was taken as a coronary flow indicator. The TIMI (Thrombolysis in Myocardial Infarction) frame count (TFC) of the culprit vessel (up to the last segment of that particular vessel) was recorded from basal and after Bivalirudin infusion. The improper engagement of guide catheter or different sizes guides for basal and subsequent angioplasty was excluded from the angio analysis. The patients who had complete procedural success were only enrolled, and final TFC was repeated after $\mathrm{PCl}$.

\section{Results}

The 50 eligible ACS patients were recruited in this study with the mean age of $54.4 \pm 14.72$ yrs. There were 46 (92\%) males and only four females in this study group. Hypertension was in 25 (50\%) and Diabetes in 20 (40\%) patients. All disruptive and biochemical parameters were mentioned in table 1. The culprit vessel lesion was in LAD in $23(46 \%)$, LCX in $15(30 \%)$ and RCA in 12 (24\%) patients (Figure 1).
Table 1. Disruptive and biochemical parameters.

\begin{tabular}{|l|c|}
\hline Variable & Value \\
\hline Total no of patients & 50 \\
\hline Age (yrs) & $54.4 \pm 14.72$ \\
\hline Female:: Male & $1:: 11.5$ \\
\hline Hypertension (\%) & $25(50 \%)$ \\
\hline Diabetes Miletus (\%) & $20(40 \%)$ \\
\hline Smoking (\%) & $5(10 \%)$ \\
\hline Obesity (\%) & $5(10 \%)$ \\
\hline Height (Cms) & $157 \pm 3$ \\
\hline Weight (Kgs) & $64 \pm 6$ \\
\hline Blood Urea (mg/dL) & $20.56 \pm 4.2$ \\
\hline Serum Creatinine (mg/dL) & $1.03 \pm 0.2$ \\
\hline Sodium (mmol/L) & $138.9 \pm 5.2$ \\
\hline Potassium (mmol/L) & $8.4 \pm 12.2$ \\
\hline Chloride & $103 \pm 4.52$ \\
\hline Random Blood Sugar & $144.8 \pm 71.4$ \\
\hline
\end{tabular}

\section{Type of lesions}

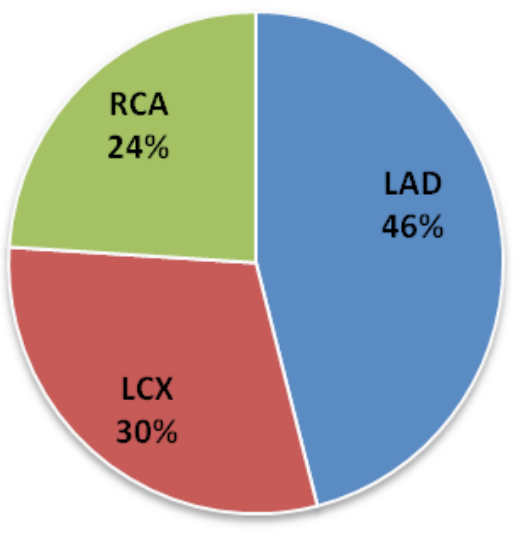

Figure 1. Culprit vessel angioplasty.

To see the significant change in the TFC we took the mean \pm SD of both (before and after) TFC and compared. Mean TFC before Bivalirudin was $16.92 \pm 6.2$ and after Bivalirudin was $11.4 \pm 3.8$ which is statistically significant $(p=<0.0001)$ (Table 2, Figure 2). We did sub-analysis for different coronary vessels for the improvement in the TFC. TFC on average for LAD lesions before bivalirudin was $17.24 \pm$ 5.9 and after bivalirudin was $12.33 \pm 4.6$, which was statistically significant ( $p=0.003$ ). Mean TFC for LCX, RCA lesions, before and after bivalirudin were not statistically significant. Details mentioned in table 3.

Table 2. TIMI Frame counts (TFC) and statistical significance value.

\begin{tabular}{|l|c|c|}
\hline Parameter & Value & p-value \\
\cline { 1 - 2 } Mean TFC before Bivalirudin & $16.92 \pm 6.2$ & \multirow{2}{*}{$<0.0001$} \\
\hline Mean TFC after Bivalirudin & $11.4 \pm 3.8$ & \\
\hline
\end{tabular}

Table 3. TIMI frame count for culprit vessel.

\begin{tabular}{|l|c|c|}
\hline Parameter & Mean \pm SD & p-value \\
\hline Mean TFC for LAD before Bivalirudin & $17.24 \pm 5.9$ & \multirow{2}{*}{0.003} \\
\cline { 1 - 2 } Mean TFC for LAD after Bivalirudin & $12.33 \pm 4.6$ & \\
\hline \multicolumn{2}{|c|}{0.145} \\
\hline Mean TFC for LCX before Bivalirudin & $13.5 \pm 4.05$ & \multirow{2}{*}{0.665} \\
\hline Mean TFC for LCX after Bivalirudin & $11.2 \pm 4.34$ & \\
\hline Mean TFC for RCA before Bivalirudin & $14.08 \pm 5.03$ & \multirow{2}{*}{ Mean TFC for RCA after Bivalirudin } \\
\hline
\end{tabular}




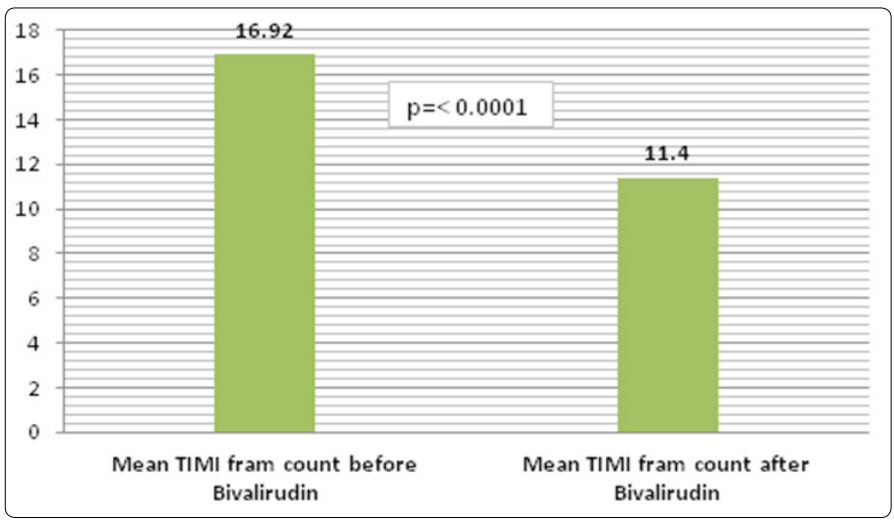

Figure 2. TIMI Frame counts in the study population.

\section{Statistical analysis}

The statistical analysis was done with Minitab version 17 (Minitab, Ltd.). The univariate analysis through student two tail t-tests was used for comparison between the two groups. The $p$-value of $\leq 0.05$ was taken as statistically significant.

\section{Discussion}

Bivalirudin is highly specific and binds thrombin at two sites, the active or catalytic site and the fibrinogen recognition site. Slow cleavage of the active-site binding portion of bivalirudin by thrombin itself results in disassociation of the bivalirudin fragments from bivalirudin and exposure of the active site (allowing thrombin to participate in clot formation). Bivalirudin inhibits both circulating and clot-bound thrombin and does not activate platelets. The 25-minute half-life of bivalirudin, together with the mechanism of action whereby thrombin is temporarily disabled but not permanently altered, leads to a superior bleeding profile, with fewer bleeds reported in all trials done with bivalirudin versus heparin in the $\mathrm{PCl}$ setting.

Indeed, clinical studies with bivalirudin have shown consistent positive results in $\mathrm{PCl}$ patients with stable angina (SA), UA, NSTEMI, and STEMI. Meta-analyses for comparing bivalirudin with unfractionated heparin or enoxaparin plus GPI showed similar mortality rates and ischemic adverse events in patients undergoing $\mathrm{PCl}$ but reduced major bleeding complications [5,6].

The Harmonizing Outcomes with Revascularization and Stents in Acute Myocardial Infarction (HORIZONS-AMI) and the European Ambulance ACS Angiography (EUROMAX) trial showed that bivalirudin primary $\mathrm{PCl}$ improved net clinical outcomes after 30 days. There were significant reductions in major bleeding and thrombocytopenia, but an increase in acute stent thrombosis, compared with heparin \pm a GPI by a combined data analysis [7].

Matrix [8] and Bright [4] showed an obvious benefit in allcause mortality where death in the bivalirudin group was significantly lower than in those receiving heparin. In the majority of the studies, the improvement in outcome was demonstrated because bivalirudin decreases the bleeding complications [9]. Other pleiotropic effects of bivalirudin were not mentioned in these trails. We did this study to find out were bivalirudin has any additional benefits than discussed before.
The TFC method has contributed to the understanding of coronary artery disease pathophysiology and has been used to assess the efficacy of intracoronary pharmacotherapy in the setting of acute coronary syndromes. TFC is a simple, cost-effective and widely applicable method and it has contributed significantly since its evolution to the understanding of the physiology and pathophysiology of coronary artery blood flow not only in an infraction but also in many other specific conditions [10].

The use of bivalirudin was associated with greater post$\mathrm{PCl}$ coronary flow reserve compared with the eptifibatide group (1.43 vs. $1.33, p=0.036$ ) as per PROTECT-TIMI 30) trial [11]. Post-procedural coronary flow and enzymatic infarct size compared with the standard intravenous route with Intracoronary bivalirudin bolus administration during primary $\mathrm{PCl}$, is safe and improves ST-segment resolution [12]. PROTECT TIMI trial [11], and Lupi A et al. [12] demonstrated post $\mathrm{PCl}$ improvement of coronary flow, but the mechanism was not discussed.

The coronary flow improvement by bivalirudin may be due to additive vasodilatory property or action on the thrombus. Aisha Harun et al. study [13] reveals that bivalirudin also has the same effect of leeching treatment with experience with pharmacologic leeching with bivalirudin for adjunct treatment of venous congestion of head and neck reconstructive flaps. Probably bivalirudin was also showing the vasodilatation as superadded effect along with antithrombotic function. If bivalirudin has vasodilatory property in addition to its anticoagulant effect, probably after $\mathrm{PCl}$, improvement of coronary flow and reserve can be explained. With that hypothesis in the background, we tested where coronary flow improvement occurs even before the $\mathrm{PCl}$. We showed in the present study that TFC before and after bivalirudin bolus followed by infusion showed the reduction in the TFC, reflecting improvement in the coronary blood flow.

Diabetes reduces coronary flow reserve [14]. John A Bittl study [15] demonstrated that the significantly higher incidence of diabetes in the bivalirudin group than in the eptifibatide groups (44.4\% vs. $36.4 \%$ ) did not interfere with the therapeutic advantage of the direct thrombin inhibitor. The primary endpoint of coronary flow reserve still favored bivalirudin treatment [15]. In our study also $40 \%$ of the patients had diabetes, but average TFC improvement before and after the bivalirudin was seen which was statistically significant $(p=0.0001)$.

On the basis of the ACUITY trial, bivalirudin monotherapy, in concert with aspirin and clopidogrel, may be considered first-line antithrombin to be started in the emergency department in patients with moderate and high-risk ACS for whom an early invasive strategy is planned [16]. Initial and post-procedural TIMI flows are known to have significant prognostic implication among the patients undergoing primary PCI for STEMI. TIMI flow 3 in STEMI patients before arriving in the cauterization laboratory to improve clinical outcome [17]. For predicting clinical outcomes, CTFC 
measurements are very useful [18]. So, to improve the TFC, our study also supports to give bivalirudin immediately for the patients who are undergoing for invasive treatment for ACS.

\section{Conclusion}

The key finding of our study is that the improvement of TFC with use of bivalirudin during $\mathrm{PCl}$. Bivalirudin seems to improve TFC before angioplasty. Further studies are required to confirm the efficiency of bivalirudin for improvement of coronary flow and to know the mechanism for improvement of coronary flow.

\section{References}

1. Centurion OA. Bivalirudin in contemporary percutaneous coronary intervention for non-st-segment elevation acute coronary syndromes: what is the current role of platelet glycoprotein iib/iiia receptor inhibitor agents? Crit Pathw Cardiol. 2011; 10(2): 87-92. doi: 10.1097/HPC.0b013e318223e35d

2. Jolly SS, Yusuf S. Which antithrombotic to use during PCI? Eur Heart J. 2010; 31(5): 522-524. doi: 10.1093/eurheartj/ehp563

3. Shahzad A, Kemp I, Mars C, et al. Unfractionated heparin versus bivalirudin in the primary percutaneous coronary intervention (HEAT-PPCI): an open-label, single center, randomised controlled trial. Lancet. 2014; 384: 1849-the HEAT PPCI trial [2] and the BRIGHT trial [3] both are favoring 1858. doi: 10.1016/S0140-6736(14)60924-7

4. Han Y, Guo J, Zheng Y, et al. Bivalirudin vs. heparin with or without tirofiban during primary percutaneous coronary intervention in acute myocardial infarction: the BRIGHT randomized clinical trial. JAMA. 2015; 313(13): 1336-1346. doi: 10.1001/jama.2015.2323

5. De Lucca G, Cassetti E, Verdoia M, Marino P. Bivalirudin as compared to unfractionated heparin among patients undergoing coronary angioplasty. Thromb Haemost. 2009; 102(3): 428-436. doi: 10.1160/TH09-05-0287

6. Lee MS, Liao $H$, Yang $T$, et al. Comparison of bivalirudin versus heparin plus glycoprotein iib/iiia inhibitors in patients undergoing an invasive strategy: a meta-analysis of randomized clinical trials. Int J Cardiol. 2011; 152(3): 369-374. doi: 10.1016/j.jijcard.2010.08.007

7. Stone GW, Mehran R, Goldstein P, et al. Bivalirudin versus heparin with or without glycoprotein iib/iiia inhibitors in patients with STEMI undergoing primary percutaneous coronary intervention: pooled patient-level analysis from the HORIZONS-AMI and euromax trials. J Am Coll Cardiol. 2015; 65(1): 27-38. doi: 10.1016/j.jacc.2014.10.029
8. Valgimigli $\mathrm{M}$, Frigoli $\mathrm{E}$, Leonardi $\mathrm{S}$, et al. Bivalirudin or unfractionated heparin in acute coronary syndromes. N Engl J Med. 2015; 373: 997-1009. doi: 10.1056/NEJMoa1507854

9. Anantha-Narayanan $M$, Anugula $D$, Gujjula NR, et al. Bivalirudin versus heparin in percutaneous coronary intervention-a systematic review and meta-analysis of randomized trials stratified by adjunctive glycoprotein llb/ Illa strategy.J Thorac Dis. 2018; 10(6): 3341-3360. doi: 10.21037/jtd.2018.05.76

10. Kunadian V, Harrigan C, Zorkun C, et al. Use of the TIMI frame count in the assessment of coronary artery blood flow and microvascular function over the past 15 years. J Thromb Thrombolysis. 2008; 27(3): 316-328. doi: $10.1007 / \mathrm{s} 11239-008-0220-3$

11. Gibson CM, Morrow DA, Murphy SA, et al. A randomized trial to evaluate the relative protection against post-percutaneous coronary intervention microvascular dysfunction, ischemia, and inflammation among antiplatelet and antithrombotic agents: the PROTECT-TIMI-30 trial. J Am Coll Cardiol. 2006; 47(12): 2364-2373. doi: 10.1016/j.jacc.2005.12.077

12. Lupi A, Rognoni A, Cavallino $C$, et al. Intracoronary vs. intravenous bivalirudin bolus in ST-elevation myocardial infarction patients treated with primary angioplasty. Eur Heart J Acute Cardiovasc Care. 2016; 5(5): 487-96. doi: 10.1177/2048872615594499

13. Harun A, Kruer RM, Lee A, Boahene K, Byrne PJ, Richmon JD. Experience with pharmacologic leeching with bivalirudin for adjunct treatment of venous congestion of head and neck reconstructive flaps. Microsurgery. 2018; 38(6): 643-650. doi: 10.1002/micr.30298

14. Akasaka $\mathrm{T}$, Yoshida $\mathrm{K}$, Hozumi $\mathrm{T}$, et al. Retinopathy identifies marked restriction of coronary flow reserve in patients with diabetes mellitus. J Am Coll Cardiol. 1997; 30: 935-941.

15. Bittl JA. The Future of an Illusion. JACC. 2006; 47(12): 2380-2383.

16. Stone GW, Bertrand $M$, Colombo A, et al. Acute Catheterization and Urgent Intervention Triage strategY (ACUITY) trial: study design and rationale. Am Heart J. 2004; 148(5): 764-75. doi: 10.1016/j.ahj.2004.04.036

17. Elbarasi $E$, Glover $C$, So $D$, et al. The influence of intial thrombolysis in myocardial infarction flow grades on outcomes of patients with STelevation Myocardial Infarction. Canad J Cardiol. 2013; 29(10): 238. doi: 10.1016/j.jjca.2013.07.384

18. Gibson CM, Murphy SA, Rizzo MJ, et al. Relationship between TIMI frame count and clinical outcomes after thrombolytic administration. Thrombolysis in Myocardial Infarction (TIMI) Study Group. Circulation. 1999, 99: 1945-1950. 